\title{
Material removal and chip formation mechanisms of UHC-steel during grinding
}

\author{
Denkena, B. ${ }^{1}$, Grove, T. $^{2}$, Göttsching, T. $^{3 *}$ \\ ${ }^{1,2,3}$ Leibniz Universität Hannover, Institute of Production Engineering and Machine Tools, An der Universität 2, \\ 30823 Garbsen, Germany, \\ *Corresponding author; E-Mail address: goettsching@ifw.uni-hannover.de
}

\begin{abstract}
The grinding process is still an important manufacturing process for the machining of automotive components. For power train components UHC-steel is a promising new innovative alloy because of its low specific density. Results from turning of UHC-steel showed that the texture of UHC-steel significantly differs from conventional steels. Furthermore extremely hard carbides, which are embedded into a soft ferrite matrix result in a UHC-steel specific machining behavior and a high tool wear rate. Therefore UHC-steel is marked as a difficult to cut material. So far there are no research results available for the grinding of UHC-steel. Therefore fundamental investigations were conducted in order to analyze the material removal and chip formation mechanisms. Scratching tests with a geometrically defined CBN cutting edge showed ductile material removal mechanisms for a single grain chip thickness variation from $\mathrm{h}_{\mathrm{cu}}=1,5 \mu \mathrm{m}$ up to $14 \mu \mathrm{m}$. Analysis of the contact zone by means of an innovative quick stop device confirm these results.
\end{abstract}

Keywords: Grinding, UHC-steel, material removal mechanisms, chip formation

\section{Introduction}

Nowadays governmental laws and an increased consumer demand for efficient cars force the automobile industry to develop engines of higher efficiency [1,2]. Therefore novel lightweight materials, such as aluminum-alloyed ultra-high carbon steels (UHC-steels) become highly interesting for this industry, especially for rotating powertrain components. UHC-steels have a density that is reduced by 10 percent compared to similar conventional construction materials like 70MnVS4. Nevertheless the other mechanical properties of those steels are on similar levels. The development of UHC-steel is based on the research and the patents of Oyama [3], Sherby [4, 5], Lesuer [6] and Taleff [7]. The steel is characterized by a high carbon content of up to 2.1 percent. Primarily UHC-steel was developed to allow superplastic forming for tool steel applications. Further research was conducted by Sherby et al. with additional elements, like $\mathrm{Al}, \mathrm{Si}$ or $\mathrm{Cr}$ [5]. By this the density was reduced and a new application for UHC-steels besides tool steel was possible. Daimler AG now focused on this material and four patents were filed, in order to create a new lightweight steel alloy. Despite the comparable long history of UHC-steels, processing of these steels has been limited to laboratory scale until recent developments. Ingot casting of UHC-steels on an industrial scale was conducted for the first time recently [8]. Besides forming, machining operations such as turning, milling or grinding are important processes within the process chain of power train components. So far only little research has been done within the production of UHC-steel. The forging of UHC-steel has been exemplarily investigated by Lesuer and Sherby et al. $[6,9]$ as well as by Pol in more detail [10]. Research on cutting of UHC-steel can only be found for turning processes $[8,11,12]$. The results showed that UHC-steels tend to brittle material removal mechanisms, when high plastic deformation occurs. The more brittle behavior is favorable to the initiation and propagation of cracks. Those cracks within the chips were detected and measured. The tool wear after the turning of UHC-steel is characterized by adhesions and chipping as well as abrasion caused by the combination of a soft ferritic matrix and embedded carbides. Moreover, oxidation marks indicate high tool temperatures. According to prior investigations by Denkena et al. [8], aluminumalloyed UHC-steels can be considered as difficult-to-cut materials. With the focus on grinding processes, it can be stated that there is no documented research for the grinding of UHC-steel. Nevertheless it is know from the grinding of other difficult-to-cut materials, such as nickel based superalloys, titanium alloys or iron aluminides that the material removal mechanisms in grinding differ significantly from common steels $[13,14,15,16,17,18]$. In order to enable a further productive processing of these materials a specific research for every material is necessary. Therefore this paper focusses on the fundamentals ofprocessing UHCsteel by means of grinding. This paper will present the material removal mechanisms that occur when grinding UHC-steel and will compare those results to the findings from turning this steel. Furthermore the chip formation during grinding of UHC-steel will be investigated with an innovative quick stop device. Those results will reveal if UHC-steels tend to brittle or ductile material removal mechanisms, which is an essential result for a further grinding tool and process design.

\section{Experimental setup}

In this chapter the experimental setup for the scratching tests and the quick stop device will be presented. Furthermore scratching and grinding tools will be described as well as the workpiece material. 


\section{$2.1 \quad$ Workpiece}

The material used in this study is an aluminum-alloyed UHC-steel, which contains fractions of manganese (2 wt $\%$ $<\mathrm{Mn}<3 \mathrm{wt} \%)$ and chromium ( $1 \mathrm{wt} \%<\mathrm{Cr}<2 \mathrm{wt} \%)$. After ingot casting the alloy is rolled to bar stocks with a diameter of $42 \mathrm{~mm}$ and then further processed to smaller samples by cutting and milling. The thermal and mechanical properties at room temperature are given in table 1 .

Table 1: Mechanical and thermal properties of an aluminum-alloyed UHC-steel [8]

\begin{tabular}{lc}
\hline Yield strength $\mathrm{R}_{\mathrm{e}}[\mathrm{MPa}]$ & $720-730$ \\
Tensile strength $\mathrm{R}_{\mathrm{m}}[\mathrm{MPa}]$ & $930-950$ \\
Failure strain A [\%] & $5-7$ \\
Hardness $[\mathrm{HV}]$ & $300-330$ \\
Heat capacity $\mathrm{c}_{\mathrm{p}}[\mathrm{J} /(\mathrm{kgK})]$ & 500 \\
Conductivity $\lambda[\mathrm{W} / \mathrm{mK}]$ & 14
\end{tabular}

The microstructure of the UHC-steel can be seen in Fig. 1. The sample was polished and etched to visualize the texture. The microstructure consists of a soft ferritic matrix with carbides, which have a hardness of over $20 \mathrm{GPa}$. UHC-steel contains of $82 \mathrm{vol} \%$ ferritic matrix, 16 vol\% $\%$ carbides and 1-2 vol\% chrome carbides [8].

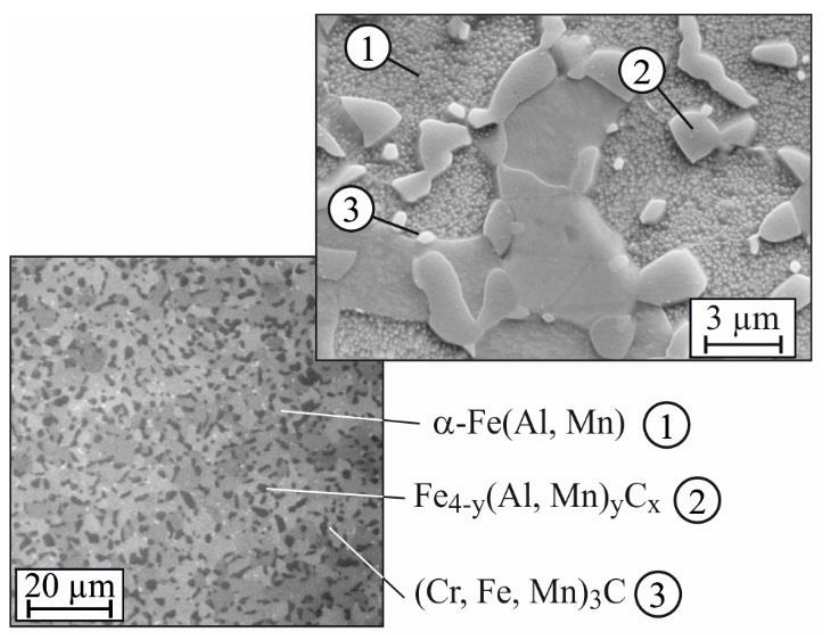

Gö/79000 C IFW

Fig. 1: Microstructure of UHC-steel [8]

\subsection{Scratching}

Scratching investigations were conducted on a Blohm Profimat MC407 grinding machine. The scratching tool was clamped into a disk with a diameter of $\mathrm{d}_{\mathrm{s}}=400 \mathrm{~mm}$. The scratching was conducted as longitudinal scratching with a process kinematic equivalent to face grinding. The process parameters cutting speed $\mathrm{v}_{\mathrm{c}}$, depth of cut $\mathrm{a}_{\mathrm{e}}$ and feed rate $v_{f}$ were adjusted by machine control. As scratching samples, UHC-steel disks with a diameter of $42 \mathrm{~mm}$ and a thickness of $5 \mathrm{~mm}$ were used. The samples were parallel ground, polished and connected by screws to a dynamometer type 9256C2 from the company Kistler. The cutting engagement results into a pulse excitation of the dynamometer and a ringing of the measured signals. Therefore the excitation was measured with an impact hammer and a correction factor was derived and was multiplied with the measured force values. By using this method it was possible to quantify the high dynamic forces, which result during the scratching process. The scratching pins have a geometrically defined cutting edge with an included angle of $120^{\circ}$. In order to guarantee comparable and reproducible scratching results a defined geometry is necessary. The pin is mounted with an inclination of $\gamma=-15^{\circ}$ in order to avoid undercuts. The cutting edge is made out of $\mathrm{CBN}$, since a diamond grain would have a chemical affinity towards steel and is therefore not suitable for any manufacturing process of steel. The experimental setup is shown in Fig. 2.
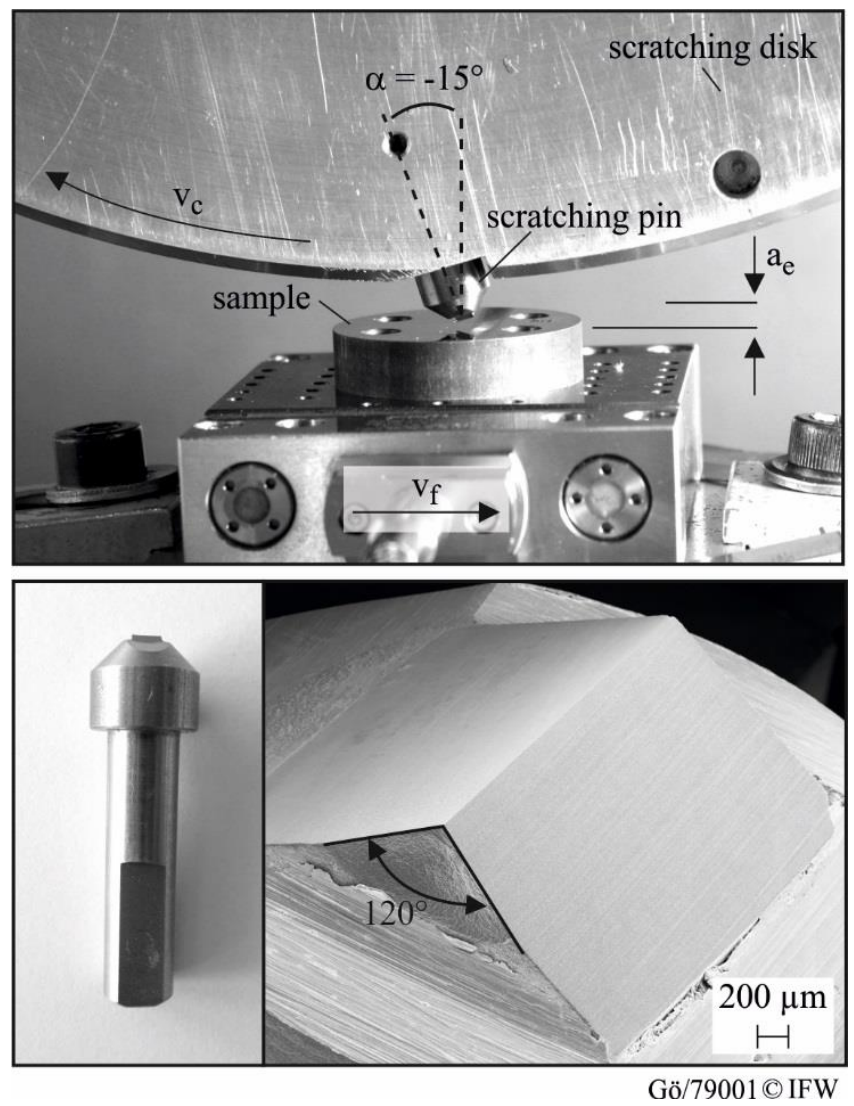

Fig. 2: Experimental setup for scratching tests and scratching tools

\subsection{Quick stop device}

In order to investigate the chip formation mechanisms in grinding, the process needs to be interrupted abruptly. This can be done by means of a quick stop device. The grinding process itself is characterized by high cutting speeds, compared to milling or turning processes. Therefore the quick stop device needs to accelerate the samples above the speed of the grinding wheel $\mathrm{v}_{\mathrm{c}}$, which ranges from about $15 \mathrm{~m} / \mathrm{s}$ up to $35 \mathrm{~m} / \mathrm{s}$ for conventional grinding wheels. Calculation and high speed measurements of the acceleration velocity showed that a captive bolt pistol supplies enough energy to 
properly interrupt a grinding process [19]. The final device was fixed into a Blohm grinding machine and is shown in Fig. 3. Guidance, braking device as well as the captive bolt pistol were clamped onto a base plate at defined positions with screws. The base plate has a length of about $700 \mathrm{~mm}$ and can be clamped in almost any grinding machine. To trigger the captive bolt pistol a manual release was installed, which was executed as soon as the grinding wheel was in contact with the sample. The grinding was conducted as a standard face grinding operation in up grinding mode. As coolant a grinding oil was used. As soon as the bolt pistol was triggered the sample was accelerated in the opposite direction of the feed into the braking device. Afterwards, the samples could be disconnected from the sliding carriage to analyze the chip roots by light microscope or SEM. The grinding tool was an aluminum oxide grinding wheel with a grain size of \# 60 and a resin bond (type: 52A $60 \mathrm{~J} 2 \mathrm{~B} 22 \mathrm{~W} 4 \mathrm{G})$. The diameter of the wheel was $\mathrm{d}_{\mathrm{s}}=350$ $\mathrm{mm}$ with a width of $20 \mathrm{~mm}$.

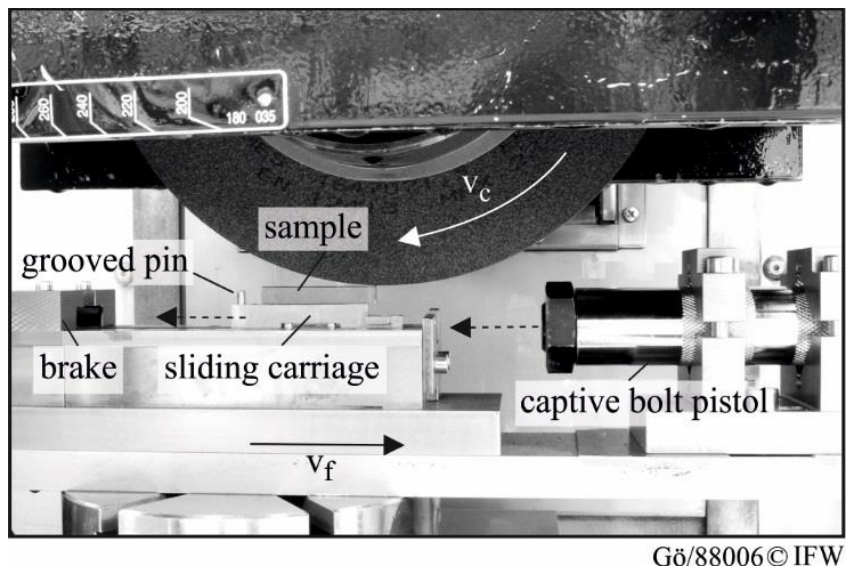

Fig. 3: Quick stop device

\section{Material removal mechanisms in single grain scratching}

The scratching process was configured by means of the single grain chip thickness $\mathrm{h}_{\mathrm{cu}}$. At first this value was computed for a standard grinding process based on the calculations from Lierse [20], which are developed on the basis of formulas from Kassen and Werner [21, 22]. By doing this it was possible to obtain a reference value that can be used for the analogy process scratching. The equation for the single grain chip thickness is derived from the outer and inner material removal rate for face grinding processes. The inner material removal rate is the sum of all grain cross sections, which are involved in the actual material removal process $\left(\mathrm{N}_{\mathrm{GV} \text {,act }}\right)$. This value can be derived from the number of grains per grinding wheel volume, called grain density $\mathrm{N}_{\mathrm{GV}}$. When grinding with super abrasive grinding wheels, it can be calculated based on the grain concentration, which is clearly marked on every grinding wheel. Such a classification does not exist for conventional grinding wheels. By using a tactile and an optical measurement device the number of cutting edges per area $\mathrm{N}_{\mathrm{GA}}$ in dependency of the depth was measured. The gradient of this concentration curve is called the grain density per volume $\mathrm{N}_{\mathrm{GV}}$. A value of $\mathrm{N}_{\mathrm{GV}}=25-30$ per $\mathrm{mm}^{3}$ was computed for a grain size of \# 60 .

The maximum single grain chip thickness, also called depth of penetration $\mathrm{z}_{\mathrm{e}}$, can be calculated according to Lierse with equation 1 by using the process parameters depth of cut $\mathrm{a}_{\mathrm{e}}$, feed rate $v_{f t}$ and cutting speed $v_{c}$ as well as the geometrical contact length $1_{\mathrm{g}}$ and the constants $\mathrm{c}_{1}$ and $\mathrm{c}_{2}$ [20]:

$$
z_{e}=h_{c u, \max }=\left(\frac{\left(c_{2}+1\right)}{N_{G V} \cdot c_{1}} \cdot \frac{a_{e} \cdot v_{f t}}{v_{c} \cdot l_{g}}\right)^{\frac{1}{c_{2}+1}}
$$

The constants $c_{1}$ and $c_{2}$ are specific grain shape factors (equation 2 and 3 ). A cutting edge angle of $\kappa=150^{\circ}$ was chosen for an aluminum oxide grain in order to solve equation 2 [23]. The constant $c_{2}$ depends on the chosen grain model. For a triangular shaped grain $c_{2}$ becomes 2 in order to solve the final equation in formula 6 [20].

The geometrical contact length $\mathrm{l}_{\mathrm{g}}$ is a function of the grinding wheel diameter $d_{s}=350 \mathrm{~mm}$ and the depth of cut and is derived with equation 4 .

$$
\begin{gathered}
c_{1}=\tan \left(\frac{\kappa}{2}\right) \\
c_{2}=2
\end{gathered}
$$

$$
l_{g}=\sqrt{d_{s} \cdot a_{e}}
$$

The number of active cutting grains $\mathrm{N}_{\mathrm{GV}}$,act can be derived from the product of grain density $\mathrm{N}_{\mathrm{GV}}$ and the depth of penetration $z_{\mathrm{e}}$ with equation 5 .

$$
N_{G V, a c t}=z_{e} \cdot N_{G V}
$$

The average load per grain, called single grain chip thickness $h_{c u}$ is calculated by applying equation 6 . 


$$
\begin{gathered}
h_{c u}=z_{e} \cdot\left(\frac{1}{c_{2}+1}\right)^{\frac{1}{c_{2}}} \\
=\left(\frac{\left(c_{2}+1\right)}{N_{G V} \cdot c_{1}} \cdot \frac{a_{e} \cdot v_{f t}}{v_{c} \cdot l_{g}}\right)^{\frac{1}{c_{2}+1}} \cdot\left(\frac{1}{c_{2}+1}\right)^{\frac{1}{c_{2}}}
\end{gathered}
$$

A face grinding process that is common for steel processing has a process parameter variation of about $\mathrm{v}_{\mathrm{c}}=10-40 \mathrm{~m} / \mathrm{s}$, $\mathrm{a}_{\mathrm{e}}=10-200 \mu \mathrm{m}$ and $\mathrm{v}_{\mathrm{ft}}=100-10,000 \mathrm{~mm} / \mathrm{min}$, which results in a single grain chip thickness of $h_{c u}=3.5-8 \mu \mathrm{m}$. Therefore for the scratching tests an average $h_{\text {cu }}$ of $5.9 \mu \mathrm{m}$ was chosen. It was increased stepwise from $1.5 \mu \mathrm{m}$ up to 14 $\mu \mathrm{m}$ in order to investigate parameter combinations beyond the calculated values as well. The single grain chip thicknesses $h_{c u}$ for scratching experiments with only one cutting edge can be setup by adjusting the scratching parameters cutting speed $v_{c}$, depth of cut $a_{e}$ and feed rate $v_{f}$ for a known scratching disk diameter $d_{s}$ with equation 7 [21].

$$
h_{c u}=2 \cdot \pi \cdot d_{s} \cdot \frac{v_{f}}{v_{c}} \cdot \sqrt{\frac{a_{e}}{d_{s}}-\left(\frac{a_{e}}{d_{s}}\right)^{2}}
$$

In the following it will be shown how this parameter influences the material removal mechanisms when scratching UHC-steel. This will be done by analyzing the obtained scratches on the samples as well as the scratching chips.

In Fig. 4 a scratch is shown resulting from longitudinal scratching of a UHC-steel sample with a single grain chip thickness of $\mathrm{h}_{\mathrm{cu}}=7.5 \mu \mathrm{m}$.

A ductile material removal mechanism can be stated along the ground of the scratch. Along the bulging at the side of the scratch small micro cracks can be found, that occur due to a low material thickness at the borders. Differences between the machined and non-machined surface of the sample can be clearly seen in the enlargement in Fig. 4. The $\kappa-$ carbides can be seen in the polished area of the sample, which are embedded equally within the $\alpha$-ferrite. Furthermore the carbides can be seen at the ground of the scratch, but no separation along the grain boundaries between carbides and ferrite. With respect to the texture of UHC-steel and the results from turning of UHC-steel, this appearance would have been likely [8]. Therefore it can be stated, that an overall ductile material removal occurs during grinding.

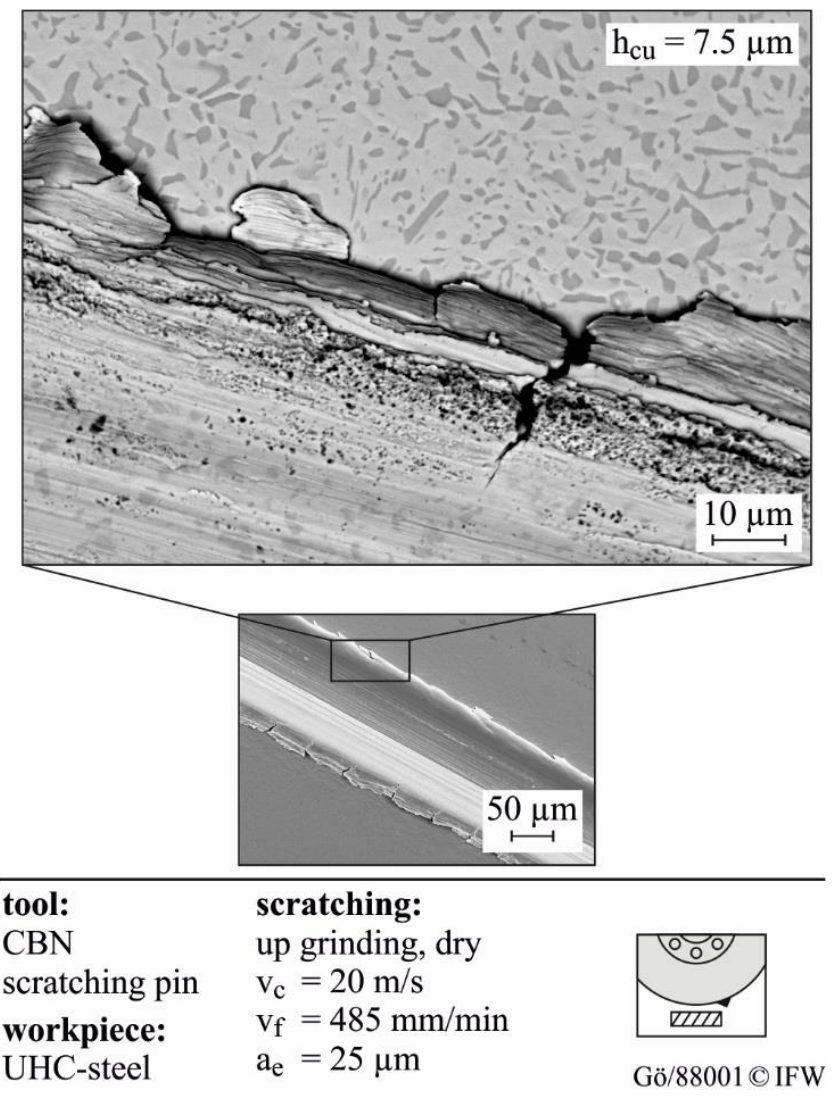

Fig. 4: Scratch in a UHC-steel sample

A further criterion for the analysis of the material removal mechanisms is the appearance of the scratching chips. Therefore the chips were collected during scratching, cleaned and embedded into resin. After that the resin samples with the chips were polished and microscope and SEM pictures were taken. An analysis of such a chip that was created during scratching with a single grain chip thickness of $\mathrm{h}_{\mathrm{cu}}=11 \mu \mathrm{m}$ is shown in Fig. 5. It can be seen that the carbides are compressed with a distinct texture. Nevertheless the degree of deformation is comparatively small, since the shape of the carbides did not change much compared to the polished sample (see Fig. 4). However no breaks can be detected along the grain boundaries of the $\kappa$-carbides, which differs from the investigation in turning of Denkena et al. [11]. 


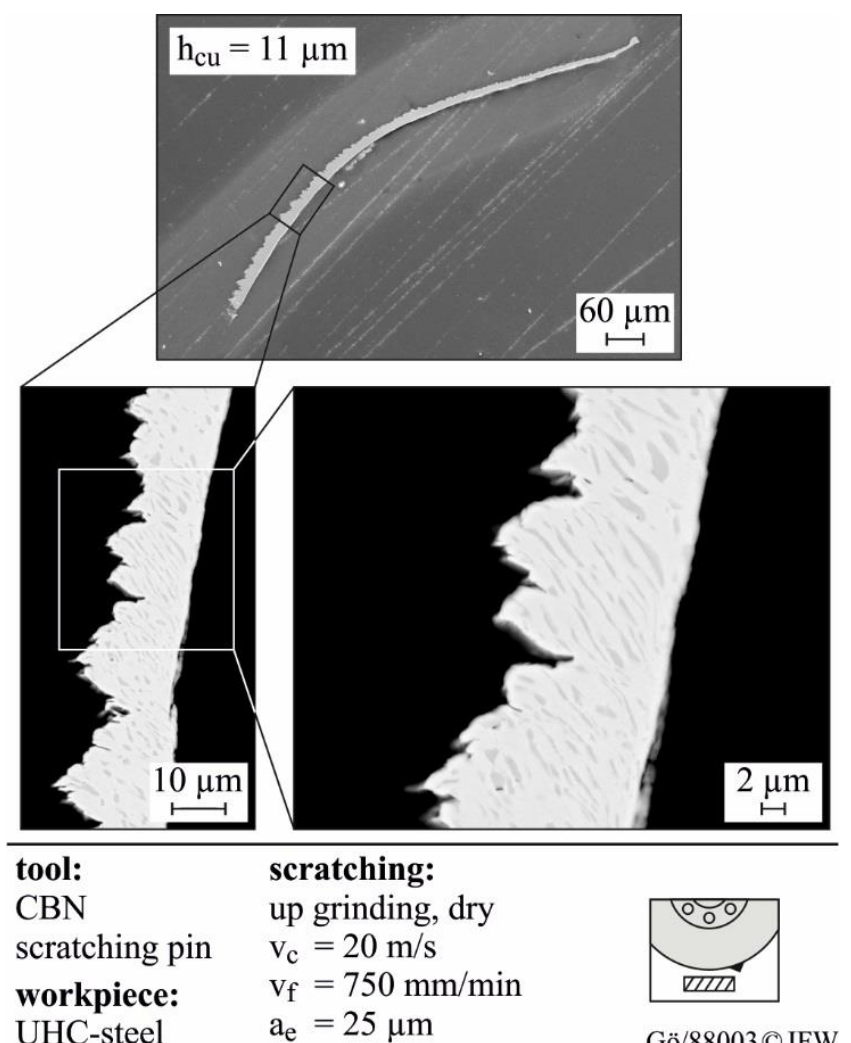

Fig. 5: Cross section of a UHC-chip

The process forces in normal and tangential direction were measured during scratching and can be used as an additional assessment criterion. During scratching the tangential force $F_{t}$ is equal to the cutting force and can be used for calculating the grinding energy per volume $\mathrm{u}$ or rather the scratching energy with equation 8 [24].

$$
u=\frac{F_{t} \cdot v_{c}}{a_{e} \cdot a_{p} \cdot v_{f t}}
$$

The cutting depth $a_{e}$ and cutting width $a_{p}$ were derived from an optical measurement of the scratch. The values for the cutting speed $v_{c}$ and the feed rate $v_{f t}$ were taken from the specific process parameters. The grinding energy per volume $\mathrm{u}$ decreases when the single grain chip thickness is increased, which can be seen in Fig. 6. For the cutting with geometrically undefined cutting edges of brittle materials such a decrease of the grinding energy per volume is characteristic for the transition between brittle and ductile material removal mechanisms. When the grinding energy is low, less energy is retained in the deformed structure or rather, less energy is needed for the recast of a new structure [25]. These findings as well as the knowledge about the deforming and the shear of the carbides within the chip confirm the assumption, that an adiabatic shear occurs, when the mechanical load is increased. In this case, less energy is needed for the recast per machined material volume, with increasing single grain chip thicknesses [26].

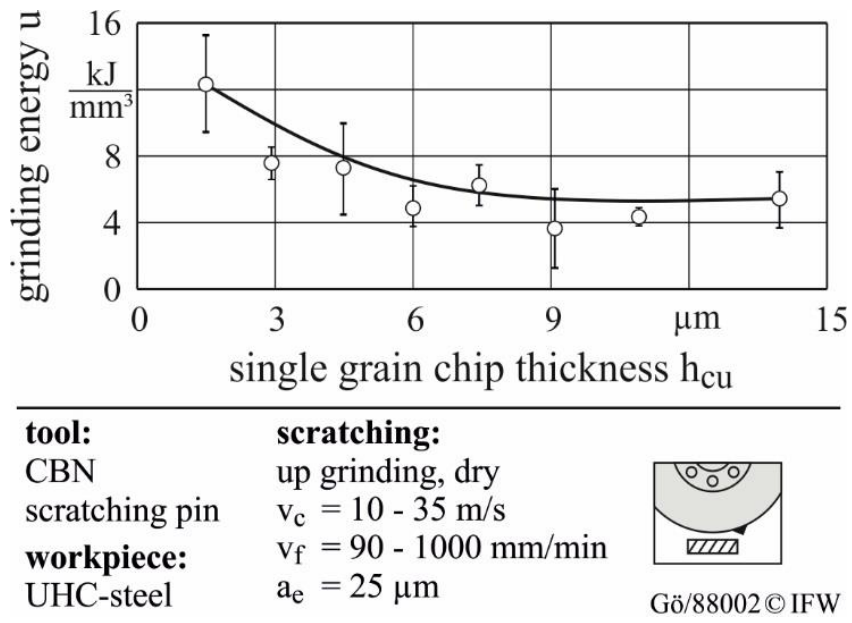

Fig. 6: Specific grinding energy in relation to the single grain chip thickness

The macroscopic shape of the chips is homogenous and uniform, which can be seen in Fig. 7. This is due to the fact, that the scratching was conducted with a defined CBN cutting edge. Moreover the longitudinal scratching creates chips with a decreasing width along the chip length. The differences between upper and bottom side of the chips can be clearly seen. The upper side has a smooth surface with little grooves, because it was in direct contact with the CBN cutting edge. The bottom side in contrast has a rough segmented structure, due to a fine shear deformation in the chip flow direction.

The compression of the chips increases, when the single grain chip thickness and therefore the mechanical load are increased. By this the chips get compressed and a reduced chip length results with a highly segmented structure. The chip compression ratio $S_{\text {st }}$ describes the relation between the length of the compressed chip in contrast to the theoretical length of the none deformed chip $1_{\mathrm{sp}}$ and is shown in Fig. 8. The theoretical chip length $1_{\mathrm{sp}}$, which corresponds to the contact arc increases from $0.5 \mathrm{~mm}$ up to $1.5 \mathrm{~mm}$, when the single grain chip thickness is increased. However the chip compression ratio decreases, due to compression of the chips. This can be explained by the chip formation mechanisms. A minimum chip thickness has to be exceeded before a chip develops. Therefore at small single grain chip thicknesses a high compression of the chips occurs with a dominant segmented structure. The chip compression ratio $\mathrm{S}_{\mathrm{st}}$ becomes constant at a single grain chip thickness of about $h_{\mathrm{cu}}=7.5 \mu \mathrm{m}$, when no further compression prevails. 


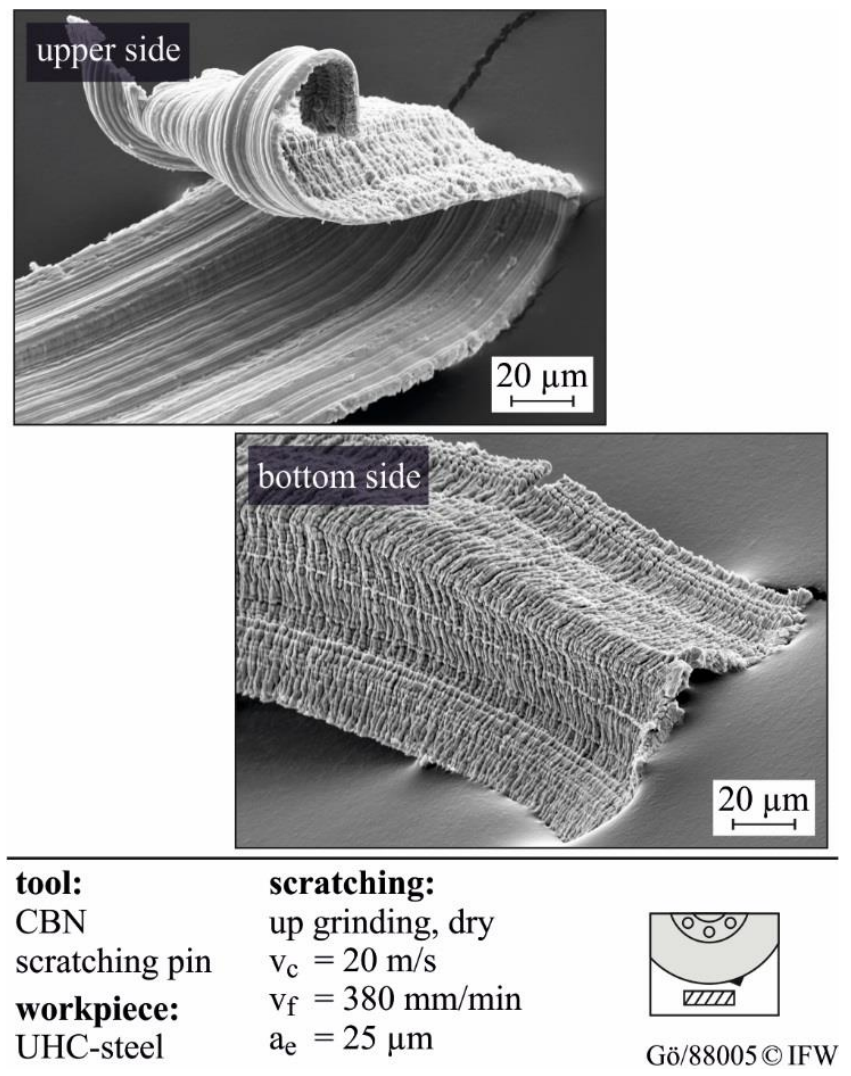

Fig. 7: Macroscopic shape of a UHC-steel chip
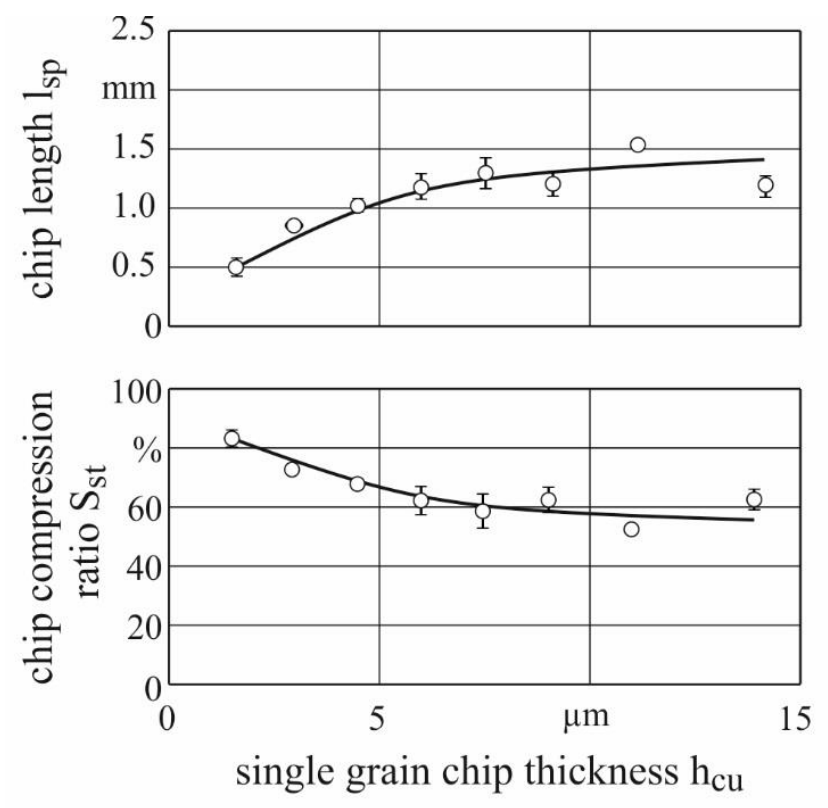

\begin{tabular}{lll}
\hline tool: & scratching: \\
CBN & up grinding, dry \\
scratching pin & $\mathrm{v}_{\mathrm{c}}=10-35 \mathrm{~m} / \mathrm{s}$ \\
workpiece: & $\mathrm{v}_{\mathrm{f}}=90-1000 \mathrm{~mm} / \mathrm{min}$ \\
UHC-steel & $\mathrm{a}_{\mathrm{e}}=25 \mu \mathrm{m}$ \\
\hline
\end{tabular}

Fig. 8: Chip length and compressed chip ratio

\section{Chip formation in grinding}

The analysis of the chip formation mechanisms during grinding of UHC-steel was executed by means of the quick stop device that was described in chapter 2.3. The device was used to interrupt face grinding processes in order to achieve a "frozen" image of the contact zone. The analysis of the chip formation mechanisms along the contact length $1_{\mathrm{g}}$ was done by means of SEM pictures. In Fig. 9 a SEM picture of the contact zone is shown after the interruption of the process. For further analysis the contact zone is divided into three sections, called entry, middle and exit section. At this SEM image the numerous grain penetrations into the surface of the sample can be clearly seen. In the following those cutting edge engagements will be analyzed in more detail.

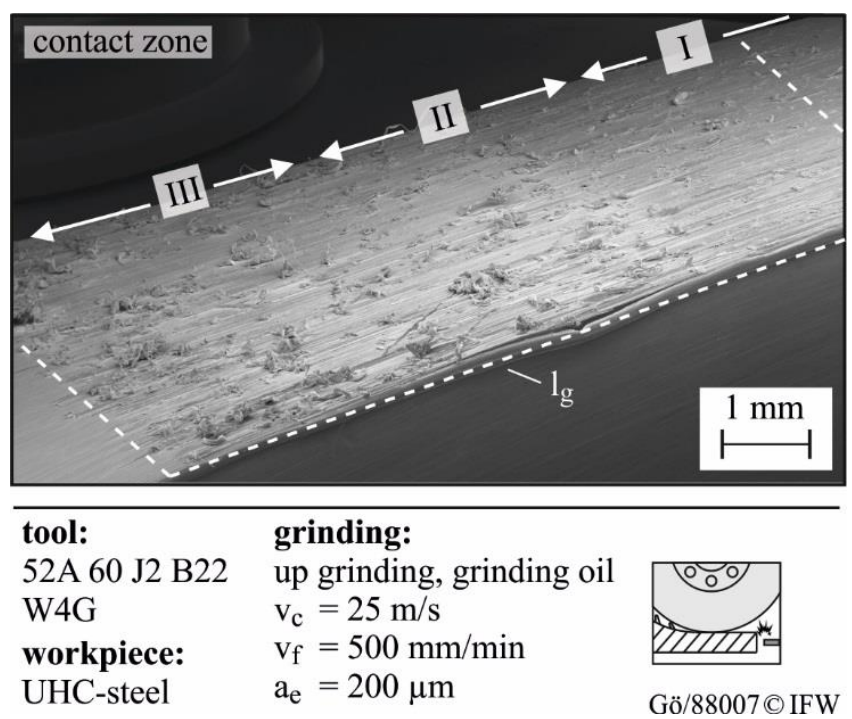

Fig. 9: Contact zone after the interruption of the grinding process

During the experiments the specific material removal rate of $\mathrm{Q}^{\prime}{ }_{\mathrm{w}}=1.66 \mathrm{~mm}^{3} / \mathrm{mms}$ was kept constant in up grinding mode. A comparatively high depth of cut of $a_{e}=200 \mu \mathrm{m}$ was chosen, in order to achieve a large geometrical contact length $1_{\mathrm{g}}$, which facilitates the optical analysis. The experiments were conducted in up grinding mode since the sample had to be accelerated in the direction of the velocity vector of the cutting speed. An analysis of the contact zone confirms the theses from Martin, who defined the chip formation mechanisms during grinding [27]. Those rubbing, ploughing, grooving and chipping mechanisms can be seen in Fig. 10.

The SEM pictures in Fig. 11 show the chip formation mechanisms in the contact zone. At the entry of the contact zone (section I and I-II) only little cutting edge engagements occur. The difference between the ground surface with a smooth topography and the actual contact zone can be clearly seen. In the entry zone chip formation mechanisms such as ploughing or grooving are dominant, since the abrasive grains have a small depth of penetration yet. 
However a large number of active cutting edges $\mathrm{N}_{\text {act }}$ are involved in the grinding process. This number is higher as known in the state of the art, according to results from existing research. Compared to the quick stop investigations of other researchers, it becomes clear that there are more active grains involved in the cutting process than estimated $[28,29]$. It shows that former quick stop devices have not been able to interrupt the grinding process with speeds higher than the cutting speed and with acceleration distances below $0.5 \mathrm{~mm}-1.5 \mathrm{~mm}$. If this had been the case similar appearances images of the contact zone would have been gained. Admittedly it has to be taken into account that different grinding wheel types and workpiece materials have been used, so that a direct comparison is only valid with restrictions.

ploughing and grooving

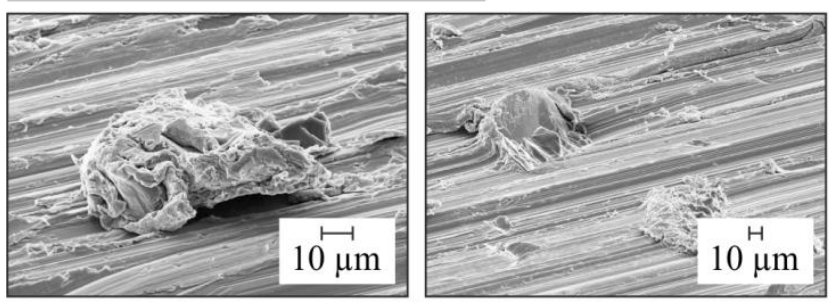

chipping

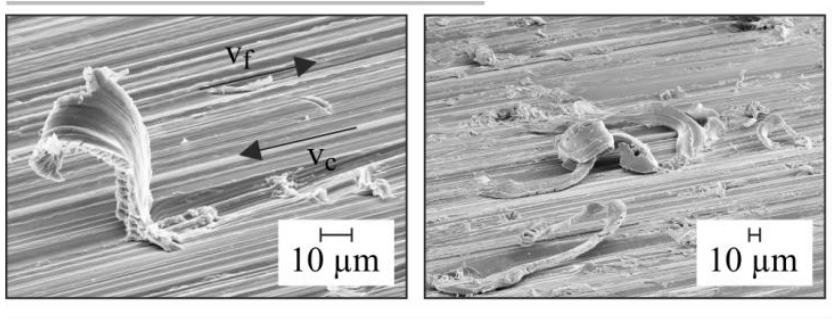

\section{tool:}

$52 \mathrm{~A} 60 \mathrm{~J} 2 \mathrm{~B} 22$

W4G grinding:

workpiece:

up grinding, grinding oil

$\mathrm{v}_{\mathrm{c}}=25 \mathrm{~m} / \mathrm{s}$

UHC-steel

$\mathrm{v}_{\mathrm{f}}=500 \mathrm{~mm} / \mathrm{min}$

$\mathrm{a}_{\mathrm{e}}=200 \mu \mathrm{m}$

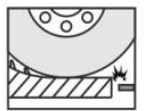

Gö/88008@ IFW

Fig. 10: Chip formation mechanisms during grinding of UHC-steel

In the middle section (II) the first actual cutting mechanisms can be found. Nevertheless, there is still a frequent amount of ploughing and grooving taking place (III). At the exit section of the contact zone the single grain chip thickness is at its maximum value and the grains face the highest load. This results in much less ploughing effects in favor of actual cutting mechanisms. Continuous and scalping chips can be found. This variety makes it evident that the chip geometry depends on the shape of the cutting edge. In dependency of the grain geometry and orientation thicker or thinner chips result. Similar to the results from scratching a smooth upper side of the chip and a rough segmented structure at the bottom side of the chip can be found. Occasionally broken chip roots or pressed down chips can be seen. This can be explained by the cleaning process, which need- ed to be applied before taking the SEM pictures as well as the filigree chip structure.
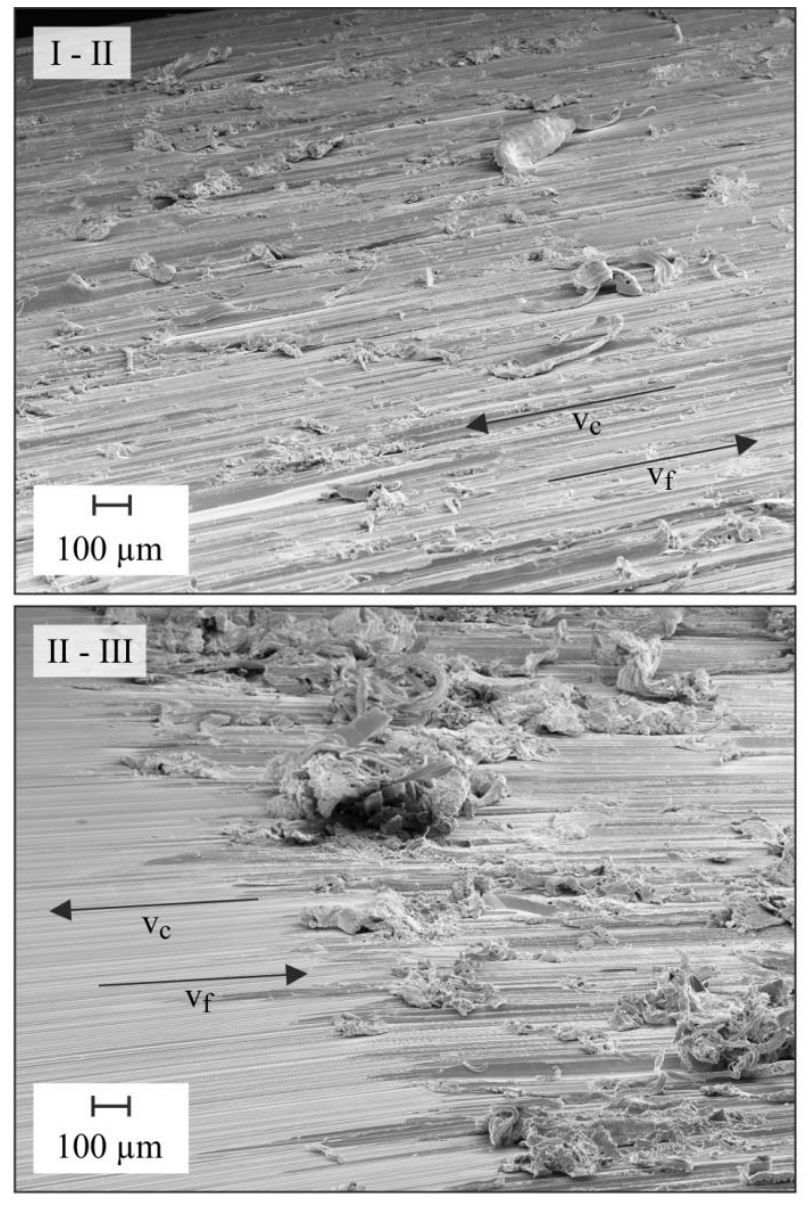

tool:

$52 \mathrm{~A} 60 \mathrm{~J} 2 \mathrm{~B} 22$

W4G

workpiece:

UHC-steel

\section{grinding:}

up grinding, grinding oil

$\mathrm{v}_{\mathrm{c}}=25 \mathrm{~m} / \mathrm{s}$

$\mathrm{v}_{\mathrm{f}}=500 \mathrm{~mm} / \mathrm{min}$

$\mathrm{a}_{\mathrm{e}}=200 \mu \mathrm{m}$

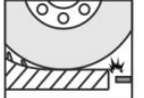

Gö/88009@ IFW
Fig. 11: Chip formation mechanisms in the contact zone

The SEM pictures in Fig. 12 also show the negative rake angle of the cutting edges, which are distinctive for grinding tools. By looking at the pictures it can be imagined how the samples were accelerated to speeds above grinding speed in order to achieve this frozen image of the grain engagement. The pictures also show an engaged abrasive grain that broke out of the grinding wheel, due to the pulsed acceleration by the captive bolt pistol. This random effect enables a further insight into the chip formation mechanisms. Besides the dominant negative rake angle of the grain, a penetration depth of the grain of nearly $20 \mu \mathrm{m}$ can be detected. 

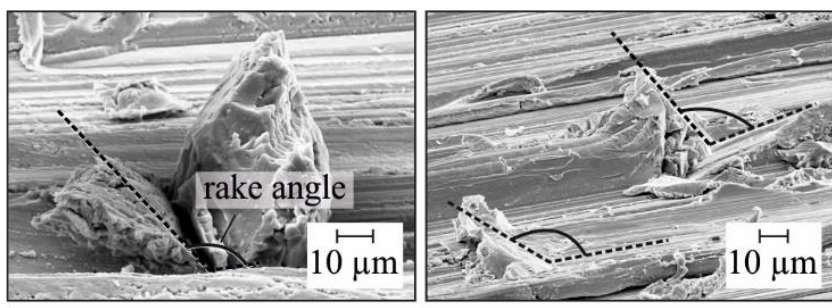

tool:

$52 \mathrm{~A} 60 \mathrm{~J} 2 \mathrm{~B} 22$

W4G

grinding:

workpiece:

UHC-steel

up grinding, grinding oil

$\mathrm{v}_{\mathrm{c}}=25 \mathrm{~m} / \mathrm{s}$

$\mathrm{v}_{\mathrm{f}}=500 \mathrm{~mm} / \mathrm{min}$

$\mathrm{a}_{\mathrm{e}}=200 \mu \mathrm{m}$

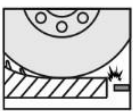

Gö/88009@ IFW

Fig. 12: Depth of penetration of a single abrasive grain

So far only ductile material removal mechanisms were detected when scratching and grinding UHC-steel. No dependency between the single grain chip thickness and the material removal mechanisms were identified. A concluding comparison between UHC-steel and the industrial applied steel 70MnVS4 shows similar chip formation mechanisms as shown in Fig. 13. Independent from the machined steel alloy chip formation mechanisms with continuous chips in combination with ductile material removal mechanisms are dominant.
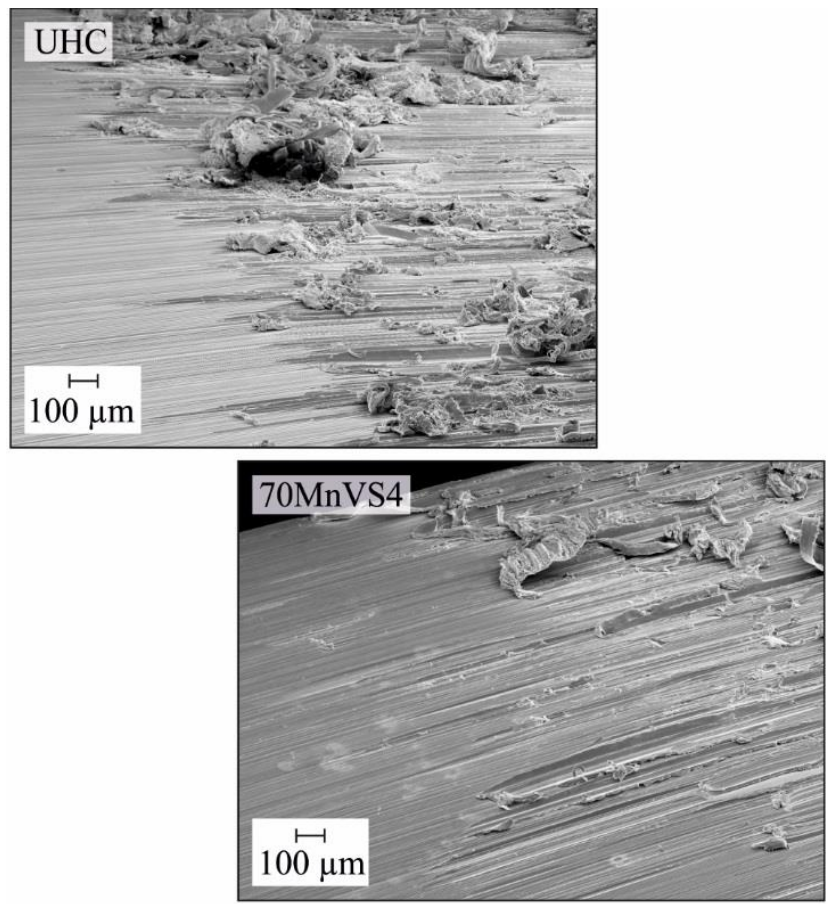

\section{tool:}

$52 \mathrm{~A} 60 \mathrm{~J} 2 \mathrm{~B} 22 \mathrm{~W} 4 \mathrm{G}$

workpiece:

UHC-steel

70MnVS40

\section{grinding:}

up grinding, grinding oil

$\mathrm{v}_{\mathrm{c}}=25 \mathrm{~m} / \mathrm{s}$

$\mathrm{v}_{\mathrm{f}}=500 \mathrm{~mm} / \mathrm{min}$

$\mathrm{a}_{\mathrm{e}}=200 \mu \mathrm{m}$

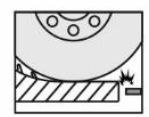

Gö/88011 C IFW

Fig. 13: Chip formation mechanisms when grinding UHCsteel and conventional steel (70MnVS4)

\section{Conclusion and outlook}

UHC-steel seems to be a promising new innovative alloy for power train components because of its low specific density. Nevertheless it was identified as a difficult to cut material in cutting investigations with defined cutting edge. So far only little research has been done in the field of processing of UHC-steel. With regard to grinding processes no documented research can be found. Therefore this paper focused on fundamental investigations regarding the material removal and chip formation mechanisms, when grinding UHC-steel. Scratching tests with a geometrically defined CBN cutting edge were conducted as well as interruptions of the grinding experiments by means of a quick stop device. As a result it can be stated, that UHC-steel shows ductile material removal mechanisms for a single grain chip thickness variation from $h_{c u}=1.5 \mu \mathrm{m}$ until $14 \mu \mathrm{m}$. Analysis of the contact zone and the predominant chip formation mechanisms confirm these results. The detailed optical analysis of the contact zone with the help of SEM micrographs impressively showed the interaction of hundreds of cutting edges along the contact zone. The knowledge about the chip formation mechanisms can be used in future to improve the grinding process, the design of grinding wheels or for the parametrization of existing grinding models. Furthermore grinding tests have to be conducted in order to analyze the resulting work piece quality after grinding of UHC-steel. This is necessary in order to evaluate, if UHCsteel can be used for the mass production of power train components. It is assumed that the low thermal conductivity of UHC-steel will lead to grinding burn and therefore will limit the productivity.

\section{Acknowledgements}

The presented investigations were undertaken with support of the German Federal Ministry of Education and Research within the Framework Concept "Research for Tomorrow's Production" (funding number: 02PN2050 ff.) and managed by the Project Management Agency Karlsruhe (PTKA).

\section{References}

[1] United Nations: Framework Convention on Climate Change - Adoption of the Paris Agreement. Conference of the Parties, Twenty-first session, Paris, 30.11.2015 11.12.2015, FCCC/CP/2015/L9/Rev.1, 2015

[2] Internationale Energieagentur: Anteil der Verkehrsträger an der weltweiten CO2-Emissionen aus der Verbrennung fossiler Brennstoffe im Jahr 2012. Statista $\mathrm{GmbH}$, www.statista.com, 2012

[3] Oyama, T.; Sherby, O.D.; et al.: Application of the divorced eutectoid transformation to the development of fine-grained, spheroidized structures in ultrahigh carbon steels. Scripta Metallurgica et Materialia 18 (8), pp. $799-$ 804, 1984 
[4] Sherby, O. D.; Young, C. M.; Conrad, M.; Walser, B.; Eldon, M.: Superplastic Ultra High Carbon Steel, US Patent \#3.951.697, 1976

[5] Sherby, O.D.; Kum, D.W.; et al.: UHCS Containing Aluminum, US Patent \#4.769.214, 1988

[6] Lesuer, D.R.; Syn, C.K.; et al.: The Case for UltrahighCarbon Steels as Structural Materials. JOM, pp. 40-46, 1993

[7] Taleff, E.M.; Nagao, M.; et al.: High-strain-rate superplasticity in ultrahigh-carbon steel containing $10 \mathrm{wt} \% \mathrm{Al}$ (UHCS-10Al). Scripta Materialia 34 (12), pp. 1919 - 1923, 1996

[8] Denkena, B.; Koehler, J.; Dittrich, M.A.: Chip Formation and Tool Wear in Turning of Aluminum-alloyed UHC-steels, Production Engineering Research and Development, 8, pp. $415-421,2014$

[9] Wittenauer, J., Schepp, P., Walser, B.: Application of Superplastic UHC-Steel for isothermal forging of machine components. TMS - Warrendale, PA, USA, 1.08.4.08.1988, Blaine, WA, 1988

[10] Pol, F.: Massivumformung dichtereduzierter UHCStähle unter nicht superplastischen Bedingungen. dissertation, RWTH Aachen, 2011

[11] Denkena, B.; Grove, T.; Dittrich, M.A.; Beiler, C.; Lahres, M.: Effects of alloying elements in UHC-steels and consequences for the machinability, CIRP Journal of Manufacturing Science and Technology, Vol. 10, pp. 102 - 109, 2015

[12] Denkena, B., Grove, T., Dittrich, M.-A.: Flow stress and temperature considerations for orthogonal cutting of an aluminium-alloyed UHC-steel. Production Engineering Research and Development, Springer Verlag, Volume 9, Issue 3, pp. $337-342,2015$

[13] Zeppenfeld, C., Klocke, F.: Speed Stroke Grinding of G-Titanium Aluminides. CIRP Annals - Manufacturing Technology, Volume 55, Issue 1, pp. 333 - 338, 2006

[14] Hood, R., Lechner, F., Aspinwall, D.K., Voice, W.: Creep Feed Grinding of Gamma Titanium Aluminide and Burn Resistant Titanium Alloys using SiC Abrasive. International Journal of Machine Tools and Manufacture, Volume 47, Issue 9, pp. 1486 - 1492, 2007

[15] Köhler, J., Moral A., Denkena, B.: Grinding of IronAluminides. Procedia CIRP, Volume 9, 2nd CIRP Global Web Conference, pp. 2 - 7, 2013

[16] Li, P.: Untersuchung und Interpretation der beim Schleifen der Nickelbasislegierung IN 738 LC induzierten Gefügeänderungen in der Randzone. dissertation, TU Berlin, 1997

[17] Österle, W., Li, P.X.: Mechanical and thermal response of nickel-base superalloy upon grinding with high removal rates. Materials Science and Engineering, A238, pp. $357-366,1997$

[18] Shi, Z., Elfizy, A., St-Pierre, B., Attia, H.: Experimental study on grinding of a nickel-based alloy using vitrified CBN wheels. Advanced Materials Research, Volume 325, pp. 134 - 139, 2011

[19] Göttsching, T., Wippermann, A., Grove, T.: Quick Stop Device to Analyze the Chip Formation Mechanisms in Face Grinding, submitted by B. Denkena. Advanced Materials Research, Vol. 1140, pp. 221 - 227, 2016

[20] Lierse T.: Mechanische und thermische Wirkung beim Schleifen keramischer Werkstoffe. dissertation, University of Hannover, 1998

[21] Kassen, G.: Beschreibung der elementaren Kinematik des Schleifvorgangs, dissertation, RWTH Aachen, 1969

[22] Werner, G.: Kinematik und Mechanik des Schleifprozesses. dissertation, RWTH Aachen, 1985

[23] Müller, N.: Ermittlung des Einsatzverhaltens von SolGel-Korund Schleifscheiben. dissertation, RWTH Aachen, 2002

[24] Malkin, S., Hwang, T.W.: Handbook of Advanced Ceramics Machining - Mechanisms for Grinding of Ceramics. Edited by Marinescu, I.D., CRC Press, Taylor \& Francis Group, Boca Raton, Florida, USA, 2007

[25] Malkin, S.: Grinding Technology - Theory and Applications of Machining with Abrasives. Ellis Horwood Ltd., Chichester, 1989

[26] Denkena, B., Tönshoff, H.K.: Spanen - Grundlagen. Springer Verlag, 3. Auflage, 2011

[27] Martin, K., Yegenoglu, K.: HSG - Technologie, Handbuch zur praktischen Anwendung. Guehring Automation GmbH, Frohnstetten, 1992

[28] Denkena, B., Köhler, J., Kästner, J., Chip formation in grinding: an experimental study, Production Engineering Research and Development (WGP), Volume 6 Number 2, pp. $107-115,2012$

[29] Denkena, B., Grove, T., Seiffert, F., Mikrogeometrische Eingriffsverhältnisse beim Längsumfangsplanschleifen. Diamond Business, 1/2015, Heft 52, pp. 62 - 72, 2015 